Jurnal Teknik Komputer AMIK BSI

Volume 7, No.2, Juli 2021

P-ISSN 2442-2436, E-ISSN: 2550-0120

Akreditasi Ristekdikti, No: 36/E/KPT/2019 (Sinta 4)

DOI: $10.31294 /$ jtk.v4i2

\title{
Rancang Bangun Aplikasi Build Up dan Break Down Cargo Valuable Berbasis Website
}

\author{
Siti Marlina ${ }^{1}$, Ahmad Setiadi ${ }^{2}$, Norma Yunita ${ }^{3}$,Yoseph Tajul Arifin ${ }^{4}$, Jekson Rudianto ${ }^{5}$ \\ ${ }^{1,3}$ Sekolah Tinggi Manajemen Informatika dan Komputer Nusa Mandiri \\ 1e-mail: siti.smr@nusamandiri.ac.id \\ 3 e-mail: norma.nyt@nusamandiri.ac.id \\ 5e-mail: jasonrudianto@yahoo.com \\ ${ }^{2,4}$ Universitas Bina Sarana Informatika \\ 2e-mail: ahmad.ams@bsi.ac.id \\ e-mail: yoseph.ypa@bsi.ac.id

\begin{tabular}{ccc}
\hline Diterima & Direvisi & Disetujui \\
$24-05-2021$ & $14-06-2021$ & $01-07-2021$ \\
\hline
\end{tabular}

\begin{abstract}
Abstrak - Pada setiap proses pengiriman barang tentunya melibatkan banyak pihak terkait, perusahaan jasa pengiriman sudah semestinya memiliki model sistem tersendiri untuk menangani masalah-masalah yang sering terjadi dimualai dari proses pendataan sampai kepada pengiriman barang. Perkembangan bisnis pada perusahaan jasa pengiriman harus diimbangi dengan sistem yang memadai, agar informasi saat proses pendataan, manifestasi sampai kepada pengiriman barang yang dibutuhkan oleh customer dapat disampaikan lebih baik. Pada perusahaan PT. Jasa Angkasa Semesta. Tbk. yang bergerak dalam bidang jasa pengiriman barang dan eskpedisi, pengelolaannya belum sepenuhnya terintegrasi melalui sistem komputer, hal ini menjadi kendala tersendiri dalam menjalankan proses bisnis perusahaan khususnya untuk menangani masalah pengiriman barang. Perancangan perangkat lunak yang memadai dalam mengelola dan menjalankan segala aktivitas perusahaan sangat dibutuhkan terutama yang berfokus pada Build Up dan Break Down Cargo Valuable yang saat ini belum terkomputerisasi dan terintegrasi dengan baik. Pendekatan yang digunakan dalam penelitian adalah pendekatan terstruktur yang menggunakan beberapa alat bantu dan teknik pengerjaan, seperti component diagram, entity relationship diagram (ERD), black box test. Penggunaan model Waterfall dalam pengembangan sistem sistem informasi tersebut diharapkan dapat meningkatkan efisiensi dalam pengolahan data build up dan break down cargo valuable.
\end{abstract}

Kata Kunci: Build Up, Break Down, Perancangan, Sistem Informasi, Web

\begin{abstract}
-
In every process of shipping goods, of course, involving many related parties, shipping service companies should have their own system models to handle problems that often occur starting from the data collection process to the delivery of goods. Business developments in shipping service companies must be balanced with an adequate system, so that information during the data collection process, manifestation to the delivery of goods needed by customers can be delivered better. At the company PT. Universal Space Services. Tbk. which is engaged in freight forwarding and expedition services, its management is not yet fully integrated through a computer system, this is a separate obstacle in carrying out the company's business processes, especially to handle the problem of shipping goods. Adequate software design in managing and carrying out all company activities is very much needed, especially those that focus on Build Up and Break Down Cargo Valuables which are currently not yet computerized and well integrated. The approach used in this research is a structured approach that uses several tools and working techniques, such as component diagrams, entity relationship diagrams (ERD), black box tests. The use of the Waterfall model in the development of information systems is expected to increase efficiency in processing data build up and break down valuable cargo

Keywords: Build Up, Break Down, Design, Information Systems, Web
\end{abstract}

\section{PENDAHULUAN}

PT Jasa Angkasa Semesta. Tbk. adalah suatu usaha yang menyediakan jasa pengiriman barang khususnya pengiriman barang-barang berharga yang akan diekspor maupun yang diimpor. Saat ini usaha tersebut masih menggunakan komputer manual yaitu menggunakan aplikasi spreadsheet yang disediakan 
oleh Microsoft. Sistem yang sekarang berjalan tidak sesuai lagi dengan perkembangan dunia teknologi dan transportasi saat ini yang telah mengalami kemajuan yang pesat. Dengan adanya perkembangan sistem informasi yang semakin baik yang bisa menyampaikan segala informasi yang diinginkan dan dibutuhkan dengan waktu yang lebih cepat. Pemanfaatan akses virtual jarak jauh, belakangan ini menjadi tren di berbagai perusahaan, hal ini terjadi karena melalui akses jarak jauh sistem tetap dapat berjalan dengan biaya yang tidak terlalu mahal. Pemetaan sistem informasi yang terencana dan matang dapat memberikan solusi terbaik dalam pemecahan masalah khususnya pada bidang pengiriman barang-barang berharga atau build up and break down cargo valuable.

Dari sistem pengiriman barang tersebut proses yang berjalan diperlukan rancangan dan pembuatan aplikasi yang berguna untuk membantu proses pelaporan build up dan break down cargo valuable dari konsumen, proses penimbangan barang, penyimpanan barang, pengantaran barang ke pesawat dan penerimaan barang dari pesawat. Rancangan aplikasi yang digunakan adalah program PHP dan Mysql. Aplikasi pengolahan data-data tersebut berbasis komputerisasi dan memiliki kelebihan dari sistem sebelumnya dalam hal kecepatan akses dan keakuratan data. Dengan kemajuan teknologi sistem informasi pada proses pengolahan tersebut, kegiatan-kegiatan pengiriman dan penerimaan barang ekspor/impor pada usaha tersebut dapat berjalan lebih efisien baik pada prosesnya maupun pada tahap pelaporannya.

Meningkatnya jumlah permintaan jasa pengiriman barang beberapa tahun terakhir ini melahirkan model bisnis baru bagi para pelakunya. Lahirnya usahausaha sejenis menjadikan persaingan pada bidang jasa pengiriman barang semakin ketat, tidak jarang pelaku usaha online yang sebelumnya berfokus pada penjualan barang, melebarkan sayap bisnisnya dengan membangun jasa ekspedisi untuk mengirimkan barang yang dipesan oleh customernya. Hal ini berakibat kepada berkurangnya target bisnis para pelaku usaha jasa pegiriman barang yang selama ini menjadi pihak ke tiga sebelum rangkaian proses bisnis berakhir.

Terdapat beberapa faktor yang menentukan pertimbangan dalam pemilihan jasa pengiriman barang seperti harga, pengemasan barang, lama pengiriman barang, banyaknya cabang, layanan sistem dalam memilih jasa pengiriman barang terbaik sesuai kebutuhan pengguna. (Oktaviani, Merlina, \& Nurmalasari, 2018). Menurut (Utami, 2015) Pengiriman barang (ekspedisi), yang semua pengolahan datanya masih manual. Ini menyebabkan kesulitan dalam mengumpulkan data, terutama data kontainer yang masuk dan keluar karena cukup banyak dan penyajian informasi yang diperlukan juga menjadi tidak efektif dan tidak efisien, bahkan kadang-kadang data tidak dapat ditemukan, menyebabkan redundansi data ketika data yang hilang direkam lagi. Akibatnya laporan yang dibutuhkan oleh manajer pemasaran seringkali tidak dapat tersedia ketika dibutuhkan dalam menyelesaikan masalah yang terjadi di PT Sinar Wijaya Kusuma. Pembuatan aplikasi yang sesuai kebutuhan akan membantu pelaku usaha untuk mencapai tujuan tersebut. Menurut (Bambang, 2013) "rancang bangun adalah proses pembangunan sistem untuk menciptakan sistem baru maupun mengganti atau memperbaiki sistem yang telah ada baik secara keseluruhan maupun hanya sebagian".

\section{Penelitian Terkait}

Menurut (Yulianti \& Destriana, 2018), hampir di setiap perusahaan jasa ekspedisi pada angkutan darat memiliki masalah yang sama. Seperti PT. Vira Surya Utama Palembang, kendala yang terjadi saat proses pencatatan data pengiriman, diantaranya duplikasi data, efisiensi dalam proses pencarian data rekaman, pencatatan faktur yang masih manual serta keterlambatan proses pembuatan laporan pengiriman barang dan laporan keuangan. Oleh karena itu, dubutuhkan suatu sistem untuk menangani masalahmasalah tersebut yang berguna untuk menyederhanakan proses pendataan pengiriman barang, pembuatan faktur pengiriman barang, dan pembuatan laporan pengiriman barang serta penyampaian laporan keuangan. Penerapan metode model waterfall serta penggunaan tools UML dalam pemodelan desain program dapat membantu menjabarkan pengembangan aplikasi kedalam bentuk diagram seperti usecase diagram, class diagram, activity diagram dan sequence diagram yang mudah difahami. Bahasa pemrograman yang digunakan dalam pengembangan sistem pada penelitian ini adalah PHP dengan integrasi database berbasis MySql Micro Dreamweaver. Hasil yang didapatkan pada penelitian ini adalah sebuah sistem informasi berbasis website yang diimplementasikan pada perusahaan PT. Vira Surya Utama Palembang yang diharapkan mampu mengatasi permasalahan yang ada pada perusahaan.

Menurut (Ramanda \& Yunita, 2019), Penerapan perkembangan teknologi pada berbagai bidang seperti bidang ekonomi dapat dirasakan dengan hadirnya berbagai bisnis e-commerce, dimana kemudahan yang ditawarkan pada platform-platform tersebut dapat menarik minat orang-orang untuk mencoba, merasakan bahkan menggunakan sebagai suatu kebiaaan baru untuk memenuhi kebutuhan berbelanja pada aplikasi tersebut. Dengan desain tampilan yang menarik dan sistem pembayaran yang dapat mempermudah kegiatan belanja, orang-orang akan lebih memilih memanfaatkan aplikasi ecommerce untuk memenuhi kebutuhannya. Pesatnya perkembangan platform ini juga berdampak pada pergerakan bisnis jasa pengiriman barang di awal kemunculannya. Hal tersebut dikarenakan proses akhir pada rangkaian kegiatan e-commerce belum 
begitu diperhatikan, terlebih volume bisnis yang belum terlalu besar sehingga permintaan akan jasa pengiriman barang masih relatif dapat diatasi dengan memanfaatkan perusahaan jasa pengiriman barang untuk mengantarkan pesanan terhadap pelanggan sebagai pihak ke tiga. Ini berbeda keadaannya saat ini, permintaan akan permintaan jasa pengiriman barang mengalami peningkatan yang sangat signifikan serta berbanding lurus dengan jumlah permintaan barang di pasar online (e-commerce), akibatnya terjadi antrian pelayanan pelanggan. Masalah ini menyebabkan pada sisi efektifitas pelayanan pelanggan. Dengan sistem komputerisasi yang baik dapat meningkatkan pelayanan dan memaksimalkan keuntungan yang didapatkan oleh perusahaan.

\section{METODOLOGI PENELITIAN}

\section{Model Waterfall}

Menurut (Pressman, 2015), model waterfall adalah model klasik yang sistematis dan berurutan dalam membangun perangkat lunak. Model Sekuensial Linier adalah nama lain model ini atau dalam istilah lain disebut siklus hidup klasik atau metode air terjun. Model ini termasuk ke dalam model generik rekayasa perangkat lunak dan pertama kali diperkenalkan oleh Winston Royce sekitar tahun 1970 sehingga sering dianggap kuno, namun merupakan model yang paling banyak digunakan dalam Rekayasa Perangkat Lunak (SE). Model ini mengambil pendekatan yang sistematis dan berurutan. Disebut air terjun karena tahapan yang dilalui harus menunggu selesainya tahapan sebelumnya dan berjalan secara berurutan.

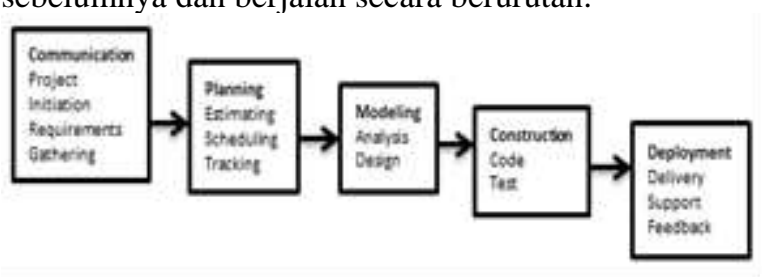

Gambar 1. Model Waterfall

\section{Communication (Project Initiation \& Requirements Gathering) \\ Sebelum memulai pekerjaan teknis, sangat perlu untuk berkomunikasi dengan pelanggan agar dapat memahami dan mencapai tujuan yang ingin dicapai. Hasil dari komunikasi ini adalah inisialisasi proyek, seperti menganalisis masalah yang dihadapi dan mengumpulkan data yang diperlukan, serta membantu mendefinisikan fitur dan fungsi perangkat lunak. Pengumpulan data tambahan juga dapat diambil dari jurnal, artikel, dan internet.}

\section{Planning (Estimating, Scheduling, Tracking)}

Tahap selanjutnya adalah tahap perencanaan yang menjelaskan perkiraan tugas teknis yang akan dilakukan, risiko yang dapat terjadi, sumber daya yang dibutuhkan untuk membuat sistem, produk kerja yang akan dihasilkan, penjadwalan pekerjaan yang akan dilakukan, dan pelacakan proses kerja sistem.

\section{Modeling (Analysis \& Design)}

Tahapan ini merupakan tahap perancangan dan pemodelan arsitektur sistem yang berfokus pada perancangan struktur data, arsitektur perangkat lunak, tampilan antarmuka, dan algoritma program. Tujuannya adalah untuk lebih memahami gambaran besar dari apa yang akan dilakukan.

\section{Construction (Code \& Test)}

Tahap konstruksi ini adalah proses menerjemahkan bentuk desain ke dalam kode atau bentuk/bahasa yang dapat dibaca mesin. Setelah pengkodean selesai dilakukan pengujian terhadap sistem dan juga kode yang telah dibuat. Tujuannya adalah untuk menemukan kesalahan yang mungkin terjadi untuk diperbaiki nantinya.

\section{Deployment}

Tahap Deployment adalah tahap implementasi perangkat lunak kepada pelanggan, pemeliharaan perangkat lunak secara berkala, perbaikan perangkat lunak, evaluasi perangkat lunak, dan pengembangan perangkat lunak berdasarkan umpan balik yang diberikan agar sistem dapat terus berjalan dan berkembang sesuai fungsinya.(Pressman, 2015).

\section{Black Box Testing}

Menurut (Sukamto \& Shalahuddin, 2014) "Black Box Testing adalah pengujian perangkat lunak dari segi spesifikasi fungsional tanpa menguji desain dan kode program. Pengujian dimaksudkan untuk mengetahui apakah fungsi, input, dan output perangkat lunak sudah sesuai dengan spesifikasi yang dibutuhkan. Black Box Test dilakukan untuk mengidentifikasi bug pada hasil pengolahan dan perilaku sistem. Black Box Test biasanya dilakukan oleh seorang tester. Black Box Test memverifikasi penanganan yang benar dari fungsi eksternal yang disediakan oleh perangkat lunak atau apakah perilaku yang diamati memenuhi harapan pengguna atau spesifikasi produk. Bentuk Black Box Testing yang paling sederhana adalah dengan memulai menjalankan perangkat lunak atau melakukan pengamatan dengan harapan mudah untuk membedakan mana hasil yang diharapkan dan mana yang tidak. Formulir ini disebut juga "ad hoc testing" setelah pengujian beberapa kali dan ditentukan bahwa masalah terjadi karena perangkat lunak dan bukan perangkat keras, kemudian informasi tersebut disampaikan kepada pihak yang bertanggung jawab kepada pihak yang bertanggung jawab untuk memperbaiki masalah tersebut. Jelaskan kronologi penelitian, termasuk desain penelitian, prosedur penelitian (dalam bentuk algoritma, Pseudocode atau lainnya), cara pengujian dan akuisisi data. Uraian program penelitian harus didukung dengan referensi, agar penjelasannya dapat diterima secara ilmiah. 


\section{HASIL DAN PEMBAHASAN}

Berdasarkan hasil analisa tentang kebutuhankebutuhan yang diperlukan, maka dapat diidentifikasikan serta diimplementasikan melalui rancangan sistem, serta rancangan layar.

3.1. Rancangan Sistem

3.1.1. Rancangan Usecase Diagram Admin

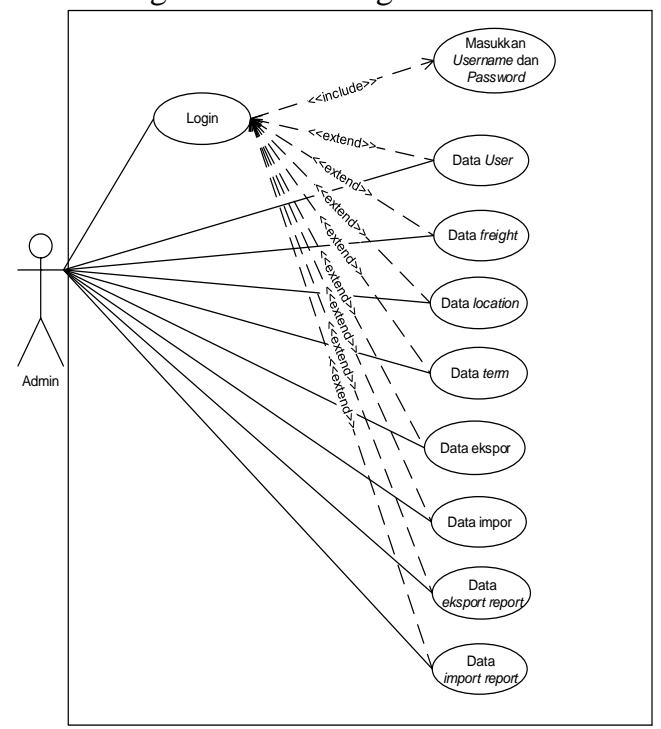

Gambar 2. Usecase Diagram Admin

3.1.2. Rancangan Usecase Diagram Customer Service Eksport

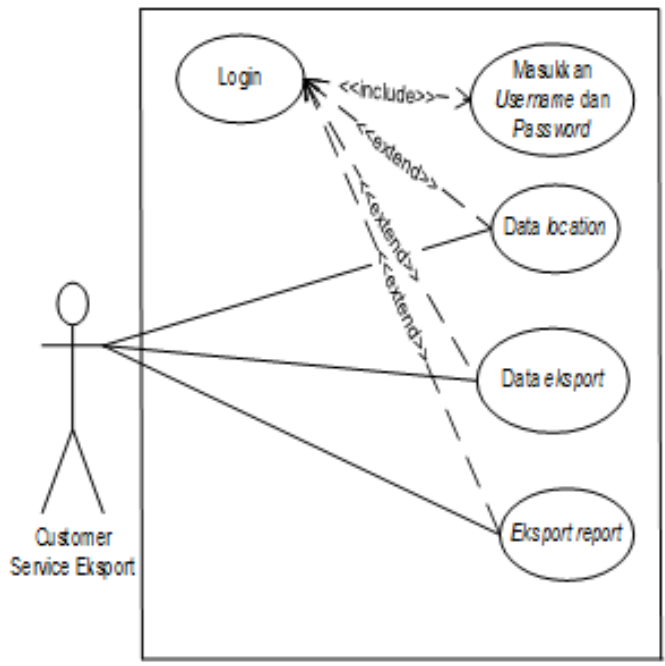

Gambar 3. Use case Diagram Halaman Bagian Customer Service Eksport

3.1.3. Rancangan Activity Diagram Transaksi Export

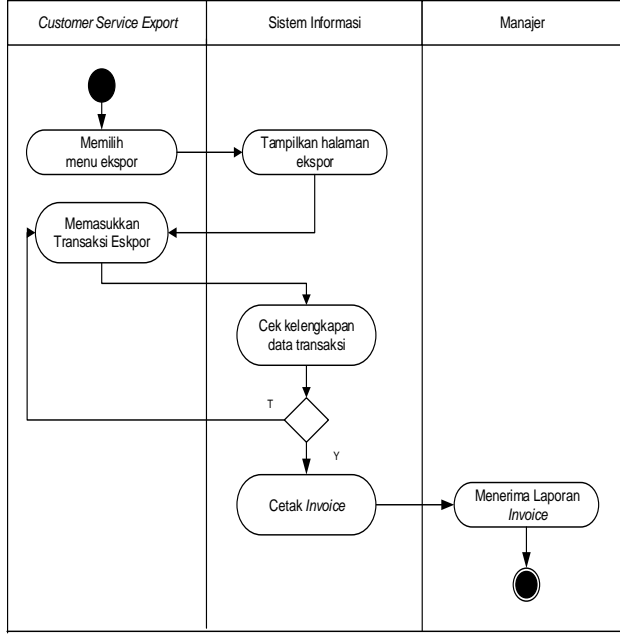

Gambar 4. Activity Diagram Transaksi export

3.1.4. Rancangan Transaksi Import

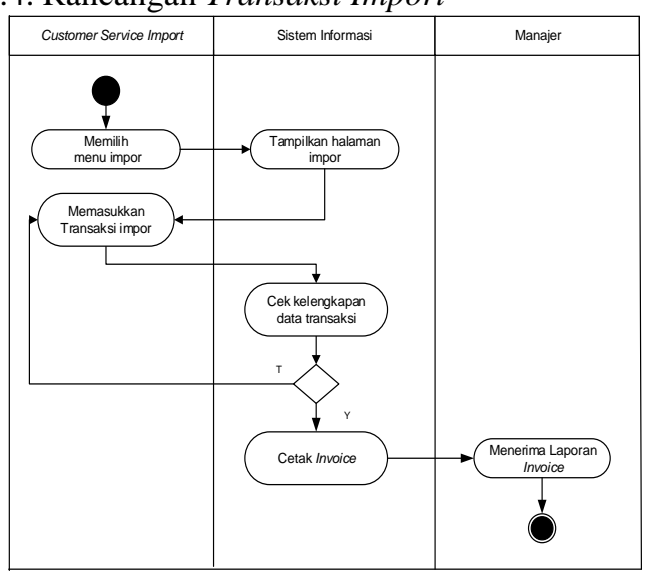

Gambar 5. Activity Diagram Transaksi Import

3.1.5.Rancangan Entity Relationship Diagram (ERD)

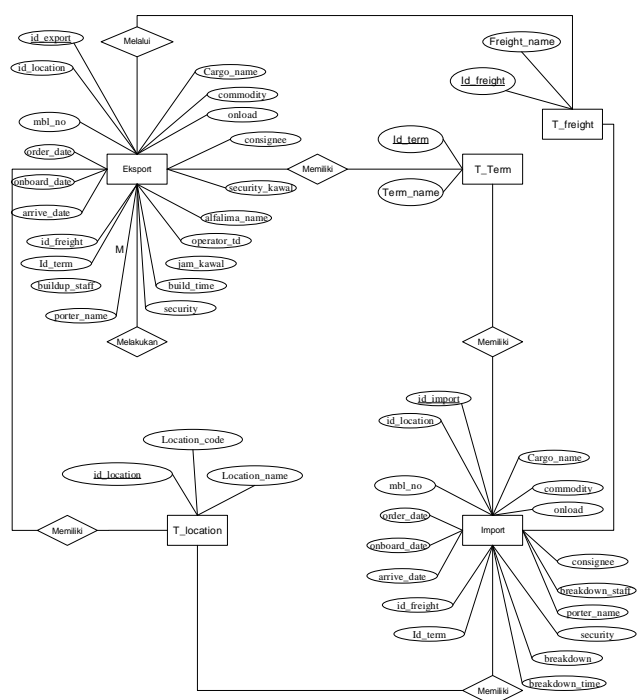

Gambar 6. Activity Diagram Entity Relationship Diagram (ERD)

3.1.6.Rancangan Entity Relationship Diagram (ERD) 


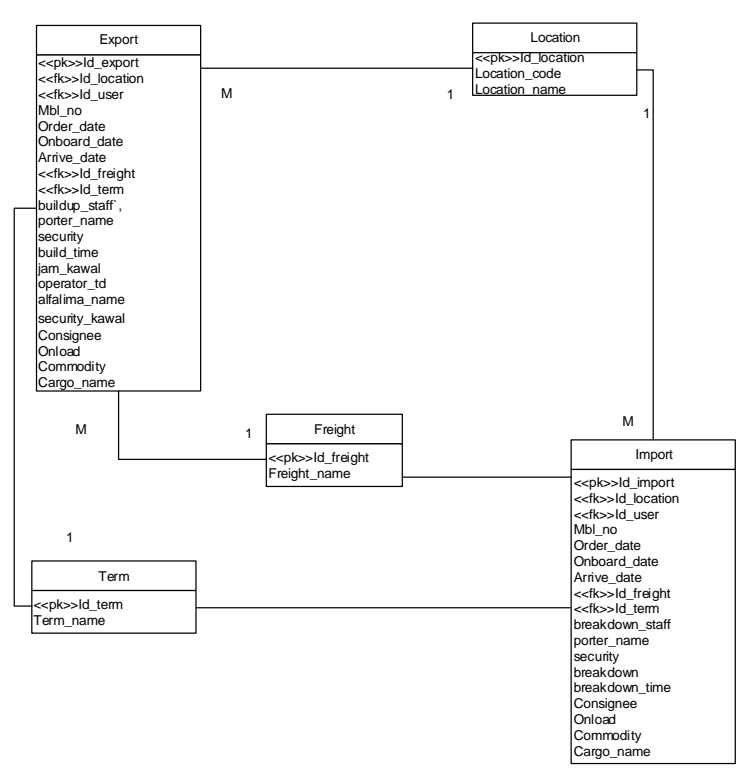

Gambar 7. Entity Relationship Diagram (ERD)

\subsection{Rancangan Layar}

\subsubsection{Halaman Index (Login)}

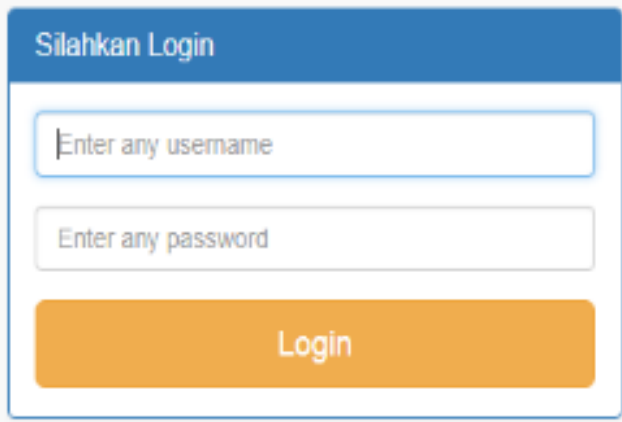

Gambar 8. Index (Login)

\subsubsection{Halaman Data User}

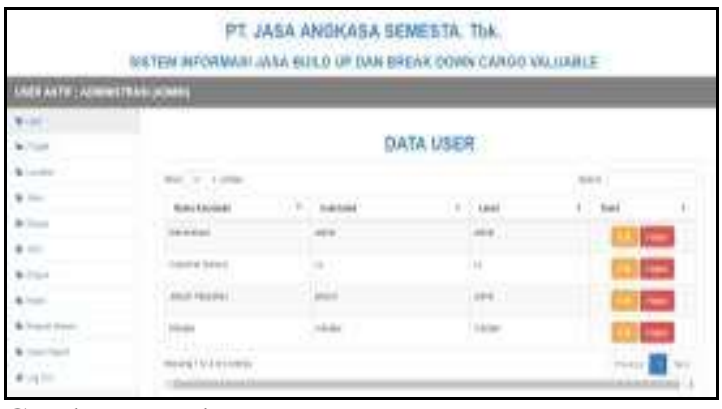

Gambar 9. Halaman Data User

\subsubsection{Halaman Data Transaksi Ekspor}

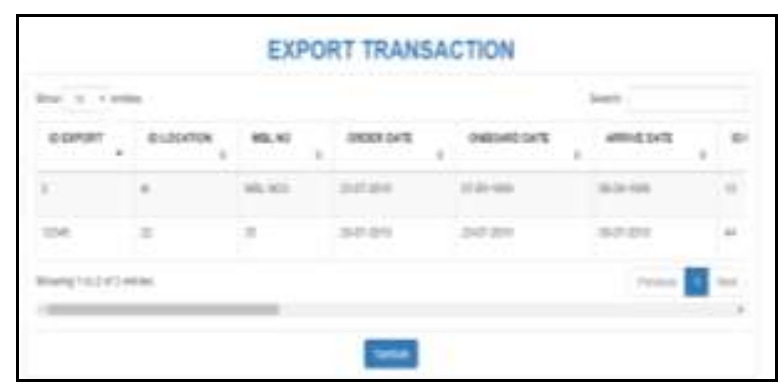

Gambar 10. Data Transaksi Ekspor

\subsubsection{Halaman Laporan Impor}

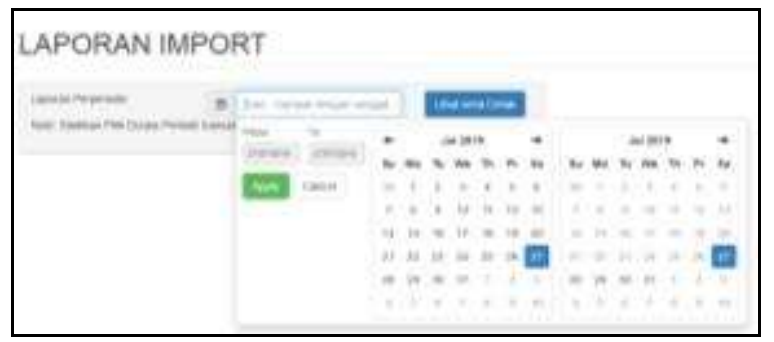

Gambar 11. Data laporan Ekspor

\section{KESIMPULAN}

Dengan adanya aplikasi sistem informasi ini dapat mengelola build up dan break down Cargo valuable dan data-data berkaitan lainnya. Aplikasi sistem informasi jasa build up dan break down Cargo valuable ini dapat mempercepat jalannya informasi dari bagian gudang kepada direksi. Aplikasi jasa build up dan break down cargo valuable ini dapat mempermudah direktur dan staff lainnya untuk memperoleh informasi tentang data penerbangan, data terminal, data pelanggan, transaksi ekspor barang, impor barang di PT. Jasa Angkasa Semesta. Tbk. Aplikasi jasa build up dan break down Cargo valuable ini dapat mempermudah pemilik dalam mengambil keputusan untuk menentukan arah perkembangan perusahaan.

\section{REFERENSI}

Bambang. (2013). Sistem Informasi Manajemen Berbasis Komputer. Jakarta: Rineka Cipta.

Oktaviani, N., Merlina, N., \& Nurmalasari. (2018). Pemilihan Jasa Pengiriman Terbaik Menggunakan Metode Simple Additive Weighting (SAW). Jurnal Sistem Dan Teknologi Informasi, 6(4), 223-229. Retrieved from

https://jurnal.untan.ac.id/index.php/justin/articl e/view/29126/75676579013

Pressman. (2015). Rekayasa Perangkat Lunak. Yogyakarta: ANDI.

Ramanda, \& Yunita. (2019). Penerapan Metode Waiting Line Pada Pelayanan Antrian Pelanggan Jasa Ekspedisi. Jurnal Sisfokom 
(Sistem Informasi Dan Komputer), 8(1). https://doi.org/https://doi.org/10.32736/sisfoko m.v8i1.586

Sukamto, \& Shalahuddin. (2014). Rekayasa Perangkat Lunak Terstruktur dan Berorientasi Objek. Bandung: Informatika Bandung.

Utami, D. Y. (2015). Perancangan Sistem Informasi Jasa Pengiriman Barang Antar Pulau Menggunakan Metode Waterfall Pada PT. Sinar Wijaya Kusuma Jakarta. Paradigma, 17(2), 15-26. Retrieved from https://ejournal.bsi.ac.id/ejurnal/index.php/par adigma/article/view/747/609

Yulianti, E., \& Destriana, G. P. (2018). Sistem Informasi Pengiriman Barang Pada PT. Vira Surya Utama Palembang. Junal Ilmiah Informatika Global, 9(1), 7-13. Retrieved from

http://ejournal.uigm.ac.id/index.php/IG/article/ view/438/520 